\title{
A comparative evaluation of the impact of population and wealth distribution on the environment of West Africa
}

\author{
Chukwuedozie K. Ajaero \\ Population Dynamics and Livelihoods Programme \\ Dept of Geography, University of Nigeria 410001, Nsukka, Nigeria \\ ajaerock@yahoo.com
}

\begin{abstract}
The debate on the relationship between population, wealth and environment has been a contentious one. In West Africa, variations exist across countries within the sub-region with regard to population size, population density, wealth distribution, and environmental stress albeit in hitherto undefined magnitude. This work is, therefore, an attempt at examining the magnitude of linkages between the variations in population, wealth and environmental stress. Findings of the study reveal disparities in the linkages between population density, wealth distribution and environmental stress across the sub-region. Based on the magnitude of environmental stress estimated from the analysis, countries of the study area are broadly grouped into areas with low, medium and high environmental stress. Consequently, this work suggests the application of country-specific measures in the quest of the sub-region to achieve sustainable development and meet up with the targets of the millennium development goals.
\end{abstract}

Keywords: Environment; linkage; population; stress; wealth; West Africa

\section{Resume}

Le dèbat portant sur le lien qui existe entre la population, les biens et, l'envionnement s'est avéré interminable. En Afrique de L'Ouest, des variations existent à travers les pays de la sous-région en matière de la taille de la population, la densité de la population, la distribution des biens, et la pression environnementale dont leurs dimensions restent non-spécifiées. Cette recherché constitue donc une tentative de scrutin de la magnitude des liaisons entre la densité de la population, la distribution des biens et la pression environnementale. Les conclusions de cette recherche révèle des inégalités de la dénsité des populations, de la distribution des biens, et de la pression environnementale à travers la sous-région. Sous la base de la magnitude de la pression environnementale révélée par l'analyse, les pays considérés dans cette recherche sont largement regroupés en trois zones de pression environnementale: basse, moyenne et élevée. Par conséquent, cette recherche propose la mise en oeuvre des mesures basées sur les spécificités de chaque pays de la sous-région dans le but d'avoir un développement durable et d'atteindre les objectifs millinaires du développement.

Mots-clés: Environnement; population; pression; biens; Afrique de l'Ouest. 


\section{Introduction}

The debate on the relationship between population, wealth and environment has been a contentious one among environmentalists, governments, economists and the public since the 1960s. The interconnectivity of population, development and environmental quality was propounded by Ehrlich in 1968 when he published the book Population Bomb. The book portrayed human population as the ultimate enemy of the environment. Although some of the assumptions such as the argument that an increase in population size leads to an increase in environmental stress in the publication have been proved to be incorrect, Ehrlich's model is still valid today.

Nevertheless, researchers such as York et al. (200I), Rosa and York (2002), Dietz et al. (2007) and Madu (2008) have shown that population and affluence are the primary drivers of various types of environmental stress. Furthermore, it is now evident that the magnitude of human induced stress on the environment depends on population size and per capita resource use, per capita income, consumption habits, technological development, social organization and the management of re-sources (Mantu, 200 I; Souza et al., 2003; Rosa et al., 2004; Nwafor, 2006; Madu, 2006, 2009).

Consequently, Nwafor and Madu (2002) have argued that at any level of development, any increase in population has a corresponding increase in energy use, resource consumption and environmental stress. Most importantly, however, and central to this study, is that it seems the populations of developing countries are more often those most vulnerable to the consequences of environmental stress. The reason for their vulnerability stems from the dependence of the majority of the population on primary economic activities such as fishing, agriculture, forestry, and hunting as their livelihoods. With the often unsustainable use of these natural resources, the environment usually suffers various types and degrees of degradation.

Accordingly, the United Nations 2005 Millennium Ecosystem Assessment Report noted that very soon most of the earth's natural resources, particularly fossil fuels, rainforests, freshwaters and fisheries would experience serious depletion and/or collapse if the present extraction and consumption trends continue unmanaged. In other words, humans are exerting enormous pressure on the ecosystem such that the sustainability of the ecosystem is no longer guaranteed, especially in the developing countries, the West African sub-region inclusive.

The West African sub-region is made up of countries whose populations depend to a large extent on natural resources for their livelihoods and sustenance. In most cases, these countries also practice mono-economy, which means that natural resources are usually depleted at alarming rates. The countries have different population characteristics, consumption habits, and natural resources. Consequently, the environment in this sub-region undergoes persistent stress albeit in varying proportions and intensities. However, the magnitude and variations of the environmental stress in the sub-region are yet to be examined. It is, therefore, germane that the source(s) of this pres- 
sure on the environment be identified and quantified, as this study intends to do. It is only with such information that policy makers, development agencies, project proponents, environmental authorities, governments and other stakeholders could initiate appropriate policies and actions aimed at ensuring the sustainability of the ecosystem of the sub-region.

\section{Methods}

This study covers the West Africa subregion with the exception of Western Sahara and Mauritania. These two countries are not included because of the inadequacy of information on them with regard to the variable inputs used for this study. Data used for this research were obtained from two sources. Population data, carbon dioxide emission values, and information on Gross National Income (GNI) per capita were obtained from "Gender, Poverty and Environmental Indicators on Africa" published by the Africa Development $\square$ ank in 2007, while the data on percentage urban population was obtained from "Rural and Urban Areas" published by the United Nations Department of Economic and Social Affairs (Population Division) in 2007. The GNI values are used because the Gross Domestic Product (GDP) values for the countries in the sub-region are not completely available. The linkage between population, wealth and environmental stress is determined with the use of Weighted Least Squares Regression using natural $\log (\mathrm{ln})$ of values of carbon dioxide emission as the dependent variable while the independent variables used are the natural log values of population size, and affluence (meas- ured by GNI per capita)

The magnitude of environmental stress is estimated using the IPAT model of Ehrlich and Holdren (1972) which is of the form:

$I=P A T$

In this model, I denotes stress on the environment represented in this work as the amount of carbon dioxide emission; $P$ represents population size; A is represented by $\mathrm{GNI} /$ capita while $T$ stands for level of technology.

The IPAT model has been used by many researchers as it delineates the impacting factors and allows for analysis of impact of individual factors (see, for example, Wetzel and Wetzel, 1995; Chertow, 200I; Shi, 2002; York et al. 2003, 2005; Gans and Jost, 2005; Lantz and Fang, 2005). However, for this study a modified version of this model called STIRPAT is used since, unlike the original IPAT model, the STIRPAT model includes an error term which according to Javonovich (2007) allows for regression analysis. STIRPAT is the Stochastic Regression of Impacts on Population, Affluence and Technology and links the limited IPAT model to suit contemporary social science theory and methods (Dietz, Rosa and York, 2007).

The STIRPAT model used for this work is of the form:

$\ln (I)=a+b(\ln (P))+c(\ln (A))+e \ldots$

Where $I$ is a measure of stress on the environment represented by carbon dioxide emission, $\mathrm{P}$ is population size, $\mathrm{A}$ is level of affluence represented by $\mathrm{GNI} /$ capita, while $\mathrm{T}$ is included in the error term (e) since appropriate, generally accepted measure or indicator of technology is disputed and thus lacking. 
$T$ as used in this work comprises other non-measurable variables such as culture, physical infrastructure, as well as other social and economic characteristics of the sub-region which could not be appropriately explained by the population, affluence and carbon dioxide emission indices. The e which is added to the effects of population, affluence and carbon dioxide emission is calculated as the antilog of the residual of our regression analysis.

In the equation, the constant $a$ is used to scale the equation, while $b$ and $c$ are the coefficients of our independent variables obtained from the regression analysis. For ease of estimation, all the input variables were converted to natural logarithms. These coefficients are, therefore, used to get the Ecological Elasticity (EE) which represents the net effect of our input variables. An Ecological Elasticity according to York et al. (2003) refers to the proportionate change in environmental stress which will result from a change in the driving variables. From the input of the regression variables, estimate of the environmental stress which results from population, wealth distribution and technological development in the West African sub-sub-region is made using the STIRPAT model.

\section{Results and discussion}

Table I below shows that there exist variations in population characteristics and level of affluence (represented by $\mathrm{GNI} /$ capita) within the West Africa subregion.

Table I Population and GNI per capita distribution in West Africa

\begin{tabular}{lcccc}
\hline Country & $\begin{array}{c}\text { Population } \\
\text { size }\end{array}$ & $\begin{array}{c}\text { Population } \\
\text { Density/Sq km }\end{array}$ & $\begin{array}{c}\text { \%Urban } \\
\text { Population }\end{array}$ & $\begin{array}{c}\text { GNI/ } \\
\text { capita(US\$) }\end{array}$ \\
\hline Denin & $8,177,200$ & 73 & 40 & 324 \\
Đurkina Faso & $12,821,700$ & 47 & 19 & 250 \\
Cote D'lvoire & $17,871,900$ & 55 & 48 & 574 \\
Gambia & $1,447,700$ & 131 & 55 & 328 \\
Ghana & $21,654,400$ & 91 & 49 & 277 \\
Liberia & $3,240,600$ & 29 & 60 & 130 \\
Mali & $13,124,000$ & 11 & 32 & 237 \\
Niger & $13,498,800$ & 11 & 16 & 153 \\
Nigeria & $128,708,900$ & 139 & 48 & 439 \\
Sierra Leone & $5,336,400$ & 74 & 37 & 210 \\
Senegal & $11,385,900$ & 58 & 42 & 489 \\
Togo & $5,988,400$ & 105 & 41 & 244 \\
Guinea & $9,201,800$ & 377 & 34 & 381 \\
Guinea $\square$ issau & $1,539,700$ & 43 & 30 & 134 \\
Cape Verde & 495,200 & 123 & 60 & 1,229 \\
\hline
\end{tabular}

I Gender, Poverty and Environmental Indicators on African Countries ( ADP, 2007)

2 Rural and Urban Areas (United Nations Dept of Economic and Social Affairs, 2007) 
Of all the countries involved in this research, only Nigeria has a population of more than 20 million persons, while a country such as Cape Verde has less than one million persons (ADP, 2007). It is also instructive to note that none of population density, percentage urban population and $\mathrm{GNI} /$ capita correlate with the population size in all the countries in the study area. In other words, there exist no identifiable patterns to explain the values of these variables that we used in estimating environmental stress in the area. For instance, Nigeria with a population of over 140 million persons has $48 \%$ of them in urban areas and has a $\mathrm{GNI} /$ capita of $\$ 439$ while Cote D'Ivoire with a population of less than 20 million persons has $55 \%$ of them in urban areas and has a $\mathrm{GNI} /$ capita of $\$ 574$. The table also shows that Cape Verde with a popula- tion of less than one million persons has $60 \%$ of them in urban areas and has a $\mathrm{GNI} /$ capita of over $\$ I, 000$. Furthermore, Mali has a population density of II persons per $\mathrm{km}^{2}$ with $32 \%$ of the population in urban areas while Guinea with a density of 377 persons per $\mathrm{km}^{2}$ has just $30 \%$ of them in urban areas. All these variations invariably affect and are also affected by the level of environmental stress associated with the countries.

These variables were subsequently converted to natural logarithms in order to eliminate the problem of heteroscedasticity. The actual values of the variables used in this study are depicted in table 2. It can still be seen from the table that even though the variables have been standardized, lack of correlation between these variables among the countries persist.

Table 2 Variables used in estimating environmental stress in West Africa

\begin{tabular}{lccc}
\hline Country & $\begin{array}{c}\text { Population size } \\
\text { (In value) }\end{array}$ & $\begin{array}{c}\text { GNI/capita } \\
\text { (In value) }\end{array}$ & $\begin{array}{c}\text { CO }_{2} \text { Emission } \\
\text { (In value) }\end{array}$ \\
\hline Denin & 15.917 & 5.781 & 14.298 \\
Durkina Faso & 16.367 & 5.521 & 13.845 \\
Cote D'lvoire & 16.699 & 6.353 & 16.165 \\
Gambia & 14.206 & 5.793 & 12.510 \\
Ghana & 16.891 & 5.624 & 15.590 \\
Liberia & 14.991 & 4.868 & 5.990 \\
Mali & 16.390 & 5.468 & 13.984 \\
Niger & 16.418 & 5.030 & 13.984 \\
Nigeria & 18.673 & 6.084 & 17.403 \\
Sierra Leone & 15.490 & 5.347 & 13.243 \\
Senegal & 16.248 & 6.192 & 15.245 \\
Togo & 15.605 & 5.497 & 14.401 \\
Guinea & 16.035 & 5.943 & 14.073 \\
Guinea $\square$ issau & 14.247 & 4.898 & 12.483 \\
Cape Verde & 13.113 & 7.114 & 11.844 \\
\hline
\end{tabular}

Source: Author's calculation 
After the analysis, the regression equation yielded the following results used in the STIRPAT equation as shown in Table 3 below.

Table 3 Results of the regression analysis used in estimation of environmental stress

\begin{tabular}{cccccc}
\hline Input variables & Regression coefficient & P-value & R2 & F & Constant \\
\hline Population size & 1.250 & 0.000 & & & \\
GNI/Capita & 2.304 & 0.000 & & &
\end{tabular}

0.641

The constant $a$ is -12.978 , coefficient of determination is $0.64 \mathrm{I}$, the $\mathrm{F}$-value is 6.538 while the $p$-value is 0.000 . Also, population and affluence variables are statistically significant at $95 \%$ level of confidence. Consequently, the regression analysis determines $64 \%$ of the environmental stresses while the coefficients representing ecological elasticity are 1.250 and 2.304 for population size and affluence respectively. Thus, the ecological elasticity is interpreted to mean that a unit change in population size results in approximately $1.3 \%$ change in environmental stresses while any unit change in affluence brings about approximately $2.3 \%$ change in environmental stresses. Since both variables have positive values it suggests that in West Africa there exist a positive correlation between population size increase and environmental stress on one hand and also a positive correlation between increase in affluence and increase in environmental stress on the other hand.

Consequently, using the input variables and with the addition of technological impact which was calculated as the antilog of the residual of the regression analysis and found to be 3.166 , the regression model used to estimate environmental stress becomes:

$\ln (I)=-12.978+1.250(\ln (P))+$

$2.304(\ln (A))+3.166$

where I represents environmental impact which is reflected by the value of carbon dioxide emission.

$\square y$ substituting the input variables from Table 2 into equation 3 for the countries under study, the specific environmental stress for each country attributable to the input variables were estimated. Table 4 shows estimates of environmental stress caused by the input variables. The values of environmental stress range from 6.799 in Guinea \issau to 14.153 in Liberia.

It can also be noted that environmental stress portrays no predictable uniform pattern in terms of causative variable(s) in the sub-region (see Tables 1 and 2 above). Using the values in Table 4, we produced a stress map of West Africa for easy visual comprehension and for spatial comparison of the estimates of environmental stress. Figure $I$ depicts the patterns of environmental stress in West Africa!

I. Mauritania and Western Sahara are not part of the study due to a dearth of data and are, therefore, not classified in the map. 
African Population Studies Vol 25, I (April 20I I)

Table 4 Magnitude of environmental stress in West Africa

\begin{tabular}{lc}
\hline \multicolumn{1}{c}{ Country } & Environmental Stress \\
\hline Liberia & 14.153 \\
Cape Verde & 11.126 \\
Nigeria & 10.144 \\
Guinea & 9.852 \\
Cote D'lvoire & 9.534 \\
†urkina Faso & 9.522 \\
Senegal & 9.519 \\
Mali & 9.291 \\
Denin & 9.105 \\
Gambia & 8.772 \\
Ghana & 8.670 \\
Sierra Leone & 8.618 \\
Niger & 8.316 \\
Togo & 7.958 \\
Guinea $\square$ issau & 6.799 \\
\hline
\end{tabular}

Source: Author's calculation

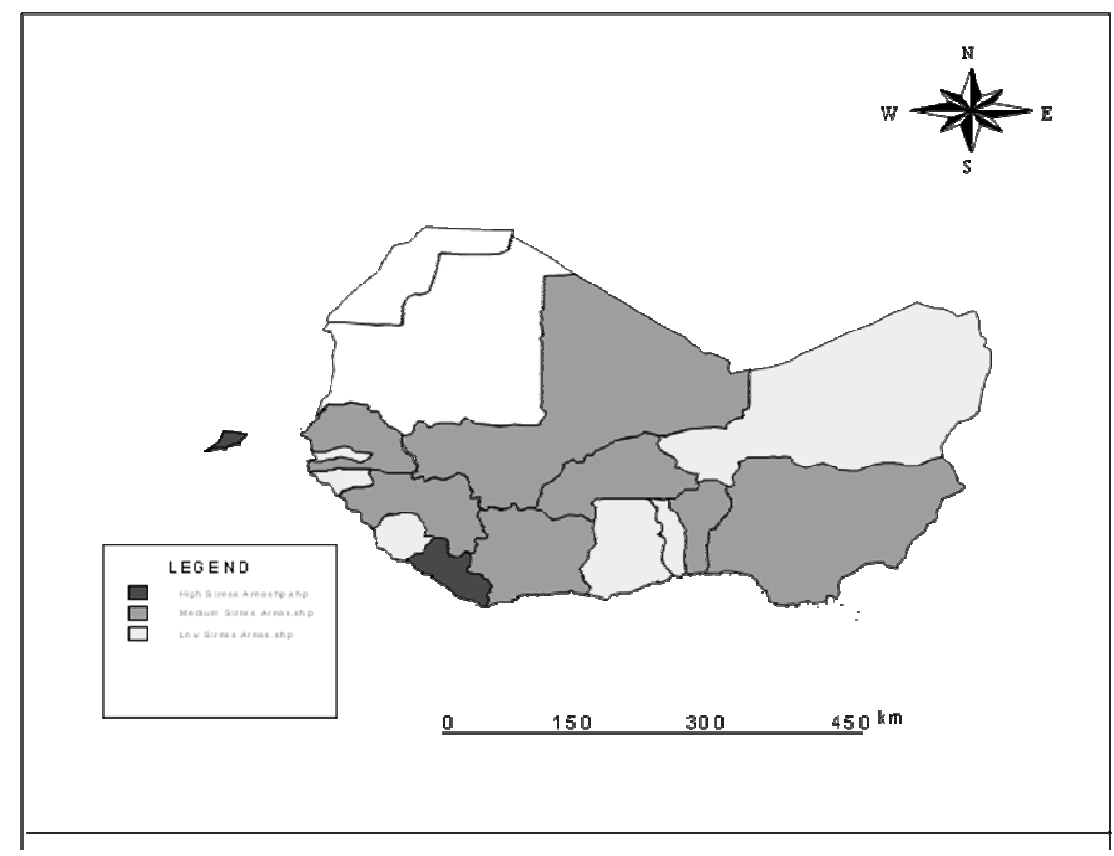

Figure I Map of environmental stress patterns in West Africa 
The countries are subsequently classified into:

- Those that experience relatively high environmental stress (with values of more than II.000). The countries in this category are Liberia and Cape Verde.

- Those that experience relatively medium environmental stress (with values of $9.00 \mathrm{I}-\mathrm{II} .00$ ). The countries in this category are Denin, Jurkina Faso, Mali, Nigeria, Senegal, Guinea and Cote D'lvoire.

- Those that experience relatively low environmental stress (with values of less than 9.000). The countries in this category are Gambia, Ghana, Niger, Sierra Leone, Togo and Guinea \issau

A comparison of Figure I with Tables I and 2 suggests that the increase or decrease in the value of environmental stress cannot be correlated with increase or decrease with any particular driving factor of the stress. In some countries, a high stress value seems to be correlated with a high population size, in others with high GNI/capita and in others with high population density and high carbon dioxide emission values. Our findings therefore suggest that the stress on the environment could not be attributed to only one of our input variables.

\section{Conclusion and \\ recommendations}

This work shows that population, technology and wealth contribute towards environmental stress in West Africa as their regression figures have positive values which are also significant at 0.05 confidence level. Furthermore, the STIRPAT model explains $64 \%$ of envi- ronmental stress due to population and wealth in West Africa. However, the magnitudes of their stress on the environment vary from country to country. On the basis of results of the analysis carried out with the STIRPAT model, West African countries are classified into countries with relatively low, relatively medium and relatively high environmental stress.

Dased on the findings of our research, we recommend the implementation of some measures in order to reduce and or manage the stress on the environment of the study area. However, the choice of any of these recommendations should depend of the relative strength of the driving factors that cause environmental stress in each of the countries. These recommendations are:

- Initiation of appropriate population policies aimed at improving the quality of life of the populace. This may be in the form proper demographic planning policies especially in the ever increasing urban areas in the study areas as well as investing in the development of the human resources in the study area.

- Efforts should be accelerated towards proper integration of environmental management practices into the socioeconomic development plan of these countries. In this regard, industries should endeavor to adopt technological practices which promote environmentally friendly modes of production.

- Furthermore, governments of these countries should insist on the conduct of environment impact assessment of any developmental project. They should 
also ensure regular audit of the impact of developmental projects on the population and environment and devise ways of minimizing their negative impacts on the environment.

- These countries should strive to engage in sustainable primary economic activities in order to minimize the adverse consequences of the indiscriminate extraction of the natural resources on the environment. Some of these practices include improved crop and grazing land management to increase soil carbon storage, restoration of cultivated peaty soils and degraded lands, afforestation, reforestation, and reduced deforestation.

- Most importantly, the populace should be appropriately informed and educated on the linkages between population, technology, affluence and environment. In this regard the populace should be made aware of the pros and cons of appropriate or otherwise extraction, utilization, and management of environmental resources in the quest by humans for socioeconomic and infrastructural development

Urgent and decisive actions are needed with regard to the recommendations made in this paper if the sustainability of the environment of our study area is to be achieved. This is in view of the global economic meltdown and the tendency of the already impoverished population to fall back more on the environment for their livelihoods and developmental activities despite the contemporary concerns on climate change (which is largely attributable to anthropogenic factors) and its associated impacts.

\section{Acknowledgement}

The author hereby acknowledges with thanks the various criticisms to this paper from participants at the $X X V I$ International Population Conference organized by IUSSP at Marrakech, Morocco from 27 September - 2 October, 2009.

\section{References}

Chertow, M (200I). The IPAT and its variants: Changing views of technology and environmental impact. Journal of Industrial Ecology. 4:13-29

Dietz, T., Rosa, E.A., and York, R.(2007). Driving the human ecological footprint. Frontiers in Ecology and the Environment. 5(I). I3-18 Ehrlich, P.(1968). The Population Bomb. New York: - Dallantine $\square o o k s$.

Ehrlich, P and Holdren, J. (1972). A bulletin dialogue on the closing circle: Critique: One dimensional ecology. Bulletin of the Atomic Scientists. 29(5): 16-27.

Gans, O. and Jost, F.(2005). Decomposing the impact of Population Growth on Environmental Deterioration. Lecture series. University of Heidelberg

Javonovich, J.V.(2007). Population versus Consumption: Determining the real driving force of environmental degradation. Accessed on July, 28, 2009 from

http://honors.wsu.edu/academics/thesis/ libraryl HonorsThesisJOVANOVICHall2007.pd $f$.

Lantz, V. and Feng, Q.(2006). Assessing income, population, and technology impacts on $\mathrm{CO}_{2}$ emissions in Canada: Where's the EKC? Eco- 
logical Economics. 57:229-238

Madu, I.A.(2006). Population distribution, disparity in living standards and environmental resource degradation in Nigeria. A paper presented at international conference on infrastructure and the environment. Sheraton Hotel Abuja, September 10-15

Madu, I.A(2009). The impacts of anthropogenic factors on the environment in Nigeria. Journal of Environmental Management. 90(3): I422-1426

Mantu, I.(200I). Implication of Population Growth for the Nigerian Economy and the Environment. Olive de L'Afrique consult, Abuja

Nwafor, J.C (2006). Environmental Impact Assessment for sustainable development: The Nigeria perspective. Enugu: Environment and Development Policy Centre for Africa (EDPCA)

Nwafor, J.C., and Madu, I.A.(2002). Issues in population and rural development. Enugu: Fulladu Publishing Company.

Rosa, E.A and York, R.(2002). Internal and external sources of environmental impacts: a com-parative analysis of the EU with other Nation's groupings. Paper presented to the conference on the European
Union in International Affairs, National Europe Centre, Australian National University, 3-4 July

Shi, A.(2003). The impact of pollution pressure on global carbon dioxide emissions, 1975-1996: evidence from pooled cross-country data. Ecological Economics. 44: 29-42

Souza, R.M., Williams,J.S., and Meyerson, F.A. $\square(2003)$. Critical links: population, health and the environment. Population $\square$ uletin 58(3). Washington DC: Population

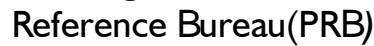

United Nations(2005). Millennium Ecosystem Assessment. Geneva: UN Press.

York, R., Rosa, E., and Dietz,T. (200I).The population and affluence elasticity of environmental impacts. Paper presented at the Pacific Sociological Association Annual Meeting in San Francisco, March 29-April I

York, R., Rosa, E., and Dietz,T (2003). STIRPAT, IPAT, and ImPACT: analytic tools for unpacking the driving forces of environmental impacts. Ecological Economics.46:35I-365

York, R., Rosa, E., and Dietz,T (2005). The Ecological Footprint Intensity of National Economies. Journal of Industrial Economics. 8: I39-154 